\title{
Teens and College Students' Purchasing Decision Factors of Denim Jeans In the United States
}

\author{
Su-Jeong Hwang Shin ${ }^{1)}$, Deborah Fowler ${ }^{1)}$, and Jinhee Lee ${ }^{2) \dagger}$ \\ ${ }^{1)}$ Dept. of Design-Apparel Design \& Manufacturing, Texas Tech University; Texas, USA \\ ${ }^{2)}$ Dept. of Fashion Design \& Apparel Industry, Wonkwang University; Iksan, Korea
}

\begin{abstract}
This study provides insight into current social media influences and purchasing power of the young generation in that the size of both of these demographic groups will impact the apparel companies and retail market for the predictable future Denim apparel companies are aware of the discretionary spending power of the $\mathrm{Y}$ and $\mathrm{Z}$ Generations. The characteristics of current teens are so similar to college-age individuals in that they have grown up with digital technology and they prefer to communicate via social networking sites. Retailers have utilized these social media platforms in order to capture the attention of the generations. Traditionally marketing campaigns have differentiated between teens and the college-age population. However, the teens actually have larger spending power and more discretionary income. A survey consisted of 32 questions pertaining to Internet media influences, influence of people, and decision factors on decisionmaking related to purchasing selection. A random sampling of 163 females responded to a set of questionnaires. Teens, like college students desire to make their own decisions when they select and purchase denim jeans. Overall $40 \%$ of them wanted to make their own decisions when purchasing their jeans, however, a significant number are influenced by their friend's opinions (34\%) and the opinions of family members (15\%). However, celebrities (10\%) had the least influence on their decisions. Teens, like colleges students make decisions based on the same decision factors: fit (63\%), cost (23\%), brand $(10 \%)$ and color $(2 \%)$. The most important factor in determining preference was "fit".
\end{abstract}

Key words: purchasing, jeans, teens, marketing, production

\section{Introduction}

Denim jeans have been being adopted as a daily fashion item and valuable commodity for the younger generations. Almost every tween, teen and college-age individual owns and wears jeans on a regular basis. Giorgio Armani stated "jeans represent democracy in fashion". The United States is not the only market where denim is important, a recent article in the Business of Fashion published in the United Kingdom, reports the demand for denim in 2013, particularly the premium denim market, is on the rebound. NPD reported the fastest growing segment is premium denim ( $\$ 75$ or more), with an estimated market value of $\$ 1.4$ billion(Wang, 2013).

Jeans have become the ubiquitous uniform of young people, so much so Teen Vogue offered "How to Wear the Eight Coolest Denim Trends this Fall" in the 2012 back to school issue. Teens replied back to the post with Tweets, Pins, emails, Stumbles, and "likes". This exemplifies the use of social media and the fashion world with this demographic. They are tuned in to social media to

†Corresponding author; Jinhee Lee

Tel. +82-63-850-6647, Fax. +82-63-850-7301

E-mail: jinhlee@wku.ac.kr give and seek immediate feedback.

The teen market in the USA is growing in size and the spending power has increased 6 to 8 percent more in 2009 than in 2008 . Sales at teen specialty stores increased to $\$ 11$ billion(Kang, 2006; Palan \& Mallalieu, 2012). The population of teens born between 1994 and 2010, Generation Y, is estimated to be more than 23 million and is the fastest growing segment in the apparel industry(Schroer, 2012). Generation Z, born after 1994, is accustomed to high-tech and multiple information sources. They cannot picture life without the Internet as it has always existed in their lifetime(Williams, 2011). In 2011, Williams reported Generation Y spent over 150 Billion USD for personal consumption, while Tweens had 43 Billion USD in spending power and accounted for an additional 600 Billion USD of family spending. The apparel market in the United Kingdom is also experiencing a similar dynamic. In 2005, a similar cohort of tweens corresponding to the American Generations of $\mathrm{Y}$ and $\mathrm{Z}$, were described as the "richest generation in history"(Lindstrom, 2008). Apparel companies became aware of the tremendous discretionary spending power of these two generations.

Fashion retailers including American Apparel, Victoria's Secret, and Reebok are using social media to gain feedback and insight from young consumers. Those retailers who are electronically con- 
nected to their customers are more competitive than those who are not(Engel et al., 2011). Some of the marketing strategies retailers and brands are using are banner ads that target people based on behavior such as their browsing habits and demographic ads based on age and gender (O'Keeffe et al., 2011). Recently the Instagram posted user names for 11 of their favorite denim aficionados they like to follow in addition to their ownposts(Lee, 2013). In addition, traditional Mobile marketing has become such an important component in retailing because these generations adopted personal mobile devices at an early age(Shankar et al., 2010). "By understanding the values that drive young consumers' relationship with the IT they use, marketers can create more compelling strategies for their brands within these interactive spaces" (Arthur et al., 2006).

Teens and the college-age population in Generation Y prefer instant messaging, texting, and interacting with friends on Facebook and Twitter(Williams \& Page, 2011). In the summer of 2012, for the Pew Research Center's Internet \& American Life Project, Pew surveyed 802 consumers aged 12 to 18 . Eighty-one percent of teens are using social networks within that group $94 \%$ stating they have Facebook accounts, 26\% Twitter, and 11\% Instagram. Further, they are willing to share photos, school names, hometowns, email addresses, and mobile phone numbers. Another 16\% shared their physical location (Internet Retailer, 5/28/13).

Based on observational studies, the lifestyle of current teens is very similar to college-age individuals in that they grew up with digital technology and they prefer to communicate via text messaging and social networking sites such as Twitter and Facebook(Berk, 2009; Ramos, 2013; Roche \& Williams, 2006). According to a recent study by Ramos(2013) on social networking, the impact of social media on teens is much greater compared to previous generations as they can easily find and post trend, fashion, and media updates from one another through various types of social networking platforms.

Marketing companies and retailers have utilized these social media platforms in order to capture the attention of these consumer populations. In the U.S., 8-18 year olds spend $25 \%$ of their media time using multiple media. In addition, $24 \%$ of $12-18$ year olds use another media while watching television (Williams \& Page, 2011). During the past five years, the numbers of tweens and teens who use social media sites has increased dramatically. Some log on to their favorite sites more than ten times a day.

Traditionally marketing campaigns have differentiated between teens and the college-age population, based on the premise that teens are not as financially independent as their college-age peers. However, research(Royer et al., 2005)has demonstrated that the teens actually have larger spending power and more discretionary income due to limited financial responsibilities. Thus, marketing teens and college students is substantial, and understanding their unique communication styles through social media is essential in appropriately marketing to this segment of the consumer market.

A recent study by Rahman(2011) found fit was the most significant and frequently mentioned attribute related to the purchase of jeans. In addition, consumers were willing to pay a higher price for specific brands based on the fit, while they rejected other brands based on the same criteria. Individuals use jeans to project or enhance their image, identity, and appearance. Because there are so many cuts of jeans, they were also able to conceal figure flaws. Herbst and Burger(2002) found brand to be the most important attribute when selecting jeans which led them to state fashion marketers should focus their marketing strategy on brand when aiming at young consumers. They also found young consumers to be price sensitive. In addition, fashion is essential in terms of peer acceptance and the ability to fit in with their social groups(Williams \& Page, 2011).

A 2005 study in the United Kingdom found this generation was very brand aware, to the point whereby they sought out specific brands rather than specific retailers. However, they would switch brands to reflect their changing preferences, stage of development or the perceived desirability of the brand with the peers(Grant \& Stephen, 2005). Noble et al.(2009) found Generation Y to be very brand and fashion conscious, but were not fickle in their brand loyalties. They instead stated trust in the brand was extremely important in their decision making. Generation Y uses the brands they purchase to blend in with the crowd or assert their individuality to their peers. In addition, they seek products that express some aspect of their own personality or image. They are aware of fashion trends, reputations of retailers, products and brand names. They also desire to make the best decision based on both price and quality.

Due to the similarity in environment that teens and college students grew up in, this research aimed to investigate the teens and college-age students' decision factors and influences on what denim items they purchase, and to provide insight into current social media influences and purchasing power of the population.

\section{Methodology}

\subsection{Sampling and data collection}

A survey was developed to determine if teens and college students have different factors influencing their decisions when purchasing denim jeans. The survey consisted of 32 questions pertaining to Internet media influences(e.g. social media Internet, $\mathrm{TV}$, magazines), influence of people(e.g. friends, family, celebrities, no influence), shopping places(e.g. online, department, discount, retail store, specialty store), purchasing decision factors(e.g. 
Table 1. Sample's ethnicity by the ages who have purchased a pair of Jeans in recent

\begin{tabular}{lcccccc}
\hline & \multicolumn{2}{c}{ Teen } & \multicolumn{2}{c}{ College } & \multicolumn{2}{l}{ Total } \\
& (Ages & $11-17)$ & (Ages & $18-30)$ & & \\
\hline Ethnics & $\mathrm{n}$ & $\%$ & $\mathrm{n}$ & $\%$ & $\mathrm{n}$ & $\%$ \\
Hispanic & 15 & $19.2 \%$ & 11 & $12.9 \%$ & 26 & $16.0 \%$ \\
Caucasian & 58 & $74.4 \%$ & 64 & $75.3 \%$ & 122 & $74.8 \%$ \\
African-American & 2 & $2.6 \%$ & 6 & $7.1 \%$ & 8 & $4.9 \%$ \\
Asian & 1 & $1.3 \%$ & 1 & $1.2 \%$ & 2 & $1.2 \%$ \\
Other & 2 & $2.6 \%$ & 3 & $3.5 \%$ & 5 & $3.1 \%$ \\
\hline Total & 78 & $100 \%$ & 85 & $100 \%$ & 163 & \\
\hline
\end{tabular}

fit, cost, brand, style, and color), and fit problems of lower body dimensions(e.g. crotch, length, hips, waist, and the entire lower body) that are related to their decisions for a pair of jeans.

Participants were from Texas Tech University, middle schools, and high schools in Lubbock, Texas. Questionnaires were collected in 2011 and 2012.A random sampling was used to select 163 females between the ages of 11-30. Table 1 shows the subject's ethnicities by the age groups, all respondents completed a set of questionnaires and stated they own at least one pair of jeans. The majority were Caucasian(74.8\%). Age groups were divided into two different generation groups: $48 \%$ teen age participants attending middle/high school(age 11-17) and 52\% college age participants(age 18-30). The participants represent both Generation $Y$ and Generation Z.

\subsection{Data statistical analysis method}

In this study, descriptive statistics were used to compare frequencies for each variable: age groups, influences, and decision factors. Contingency tables and Chi-square test with Likelihood ratio were used at $95 \%$ confidence level to find the following significances between teens and college students: Internet/media influences, influence people, decision factors, and fit problems related to their decisions when purchasing a pair of jeans.

\section{Results}

\subsection{Teens and College Students' Shopping Place Preferences}

Teens and college students were asked where they usually shop for a pair of jeans. Table 2 shows the respondent's preferences when shopping for denim jeans. In this study, $35.6 \%$ of the respondents shop at department stores. Both teens and college students prefer to purchase denim jeans at department stores, retail stores, or specialty stores. However, the online store was the least favor of shopping place for both groups to purchase a pair of jeans. Only
Table 2. Teens and college students shopping place preferences for denim jeans

\begin{tabular}{lcccccc}
\hline & \multicolumn{2}{c}{ Teen } & \multicolumn{2}{c}{ College } & \multicolumn{2}{c}{ Total } \\
\hline Shopping place preferences & $\mathrm{n}$ & $\%$ & $\mathrm{n}$ & $\%$ & $\mathrm{n}$ & $\%$ \\
Department & 28 & $35.9 \%$ & 30 & $35.3 \%$ & 58 & $35.6 \%$ \\
Online & 0 & $0.0 \%$ & 5 & $5.9 \%$ & 5 & $3.1 \%$ \\
Discount store & 7 & $9.0 \%$ & 6 & $7.1 \%$ & 13 & $8.0 \%$ \\
Retail store & 23 & $29.5 \%$ & 23 & $27.1 \%$ & 46 & $28.2 \%$ \\
Specialty store & 20 & $25.6 \%$ & 21 & $24.7 \%$ & 41 & $25.2 \%$ \\
\hline & 78 & $100 \%$ & 85 & $100 \%$ & 163 & $100 \%$ \\
\hline
\end{tabular}

$5.9 \%$ of college students shop from online store.

\subsection{Teens and College Students Media Influences}

Media influences were examined to determine if media influences teens and college students when selecting a certain style of denim jeans. In this study, we found that there was a significant difference of media influences between teens and college students $\left(\chi^{2}=9.451, p<.05\right)$. In this study, $50 \%$ of teens answered that none of media sources influenced them to make up their mind to look for a certain style.

Table 3 shows the difference of media influences between teens and college students. Our results concluded overall media impacted on teens' selections of denim jeans less than college students. For example, while $31 \%$ of college students stated that TV had a significant influence, only $14 \%$ of teens identified TV as having influence when purchase an apparel item.

As shown in Table 3, fashion magazines had significantly greater influence on both generations with teens( $31 \%$ ) and collegeaged participants(34\%). Even though they spend many hours surfing the Internet and social media, they were more likely to purchase fashion jeans found in magazines as compared to TV and Internet influences. When we consider a current stream of social media and Internet usages in for all ages, this result may be counter to the expectation of increasing online sales in the apparel industry. How-

Table 3. Teens and college students media influences on purchasing denim jeans

\begin{tabular}{|c|c|c|c|c|c|c|c|}
\hline & Teen & & College & & Total & & 2 \\
\hline Media Influences & $\mathrm{n}$ & $\%$ & $\mathrm{n}$ & $\%$ & $\mathrm{n}$ & $\%$ & \\
\hline $\mathrm{TV}$ & 11 & $14 \%$ & 26 & $31 \%$ & 37 & $23 \%$ & \\
\hline Internet & 3 & $4 \%$ & 3 & $4 \%$ & 6 & $4 \%$ & \\
\hline Radio & 1 & $1 \%$ & 0 & $0 \%$ & 1 & $1 \%$ & $9.451^{*}$ \\
\hline Magazine & 24 & $31 \%$ & 29 & $34 \%$ & 53 & $33 \%$ & \\
\hline None & 39 & $50 \%$ & 27 & $32 \%$ & 66 & $40 \%$ & \\
\hline Total & 78 & $100 \%$ & 85 & $100 \%$ & 163 & $100 \%$ & \\
\hline
\end{tabular}


Table 4. Teens and college students personal influences on purchasing denim jeans

\begin{tabular}{lcccccc}
\hline & \multicolumn{2}{c}{ Teen } & \multicolumn{2}{c}{ College } & \multicolumn{2}{c}{ Total } \\
\hline Personal Influences & $\mathrm{N}$ & $\%$ & $\mathrm{n}$ & $\%$ & $\mathrm{n}$ & $\%$ \\
\hline Friends & 27 & $34.6 \%$ & 29 & $34.1 \%$ & 56 & $34.4 \%$ \\
Family & 17 & $21.8 \%$ & 8 & $9.4 \%$ & 25 & $15.3 \%$ \\
Celebrities & 4 & $5.1 \%$ & 12 & $14.1 \%$ & 16 & $9.8 \%$ \\
Nobody & 30 & $38.5 \%$ & 36 & $42.4 \%$ & 66 & $40.5 \%$ \\
\hline Total & 78 & $100 \%$ & 85 & $100 \%$ & 163 & $100 \%$ \\
\hline
\end{tabular}

ever, only $4 \%$ of participants identified that Internet media influences their decisions to purchase a pair of jeans.

\subsection{Teens and College Students Personal Influences}

Table 4 compares the personal influences which impact teens and college students when shopping for denim jeans. When a chisquare test was used for significance testing the relation to personal influences, it was found that there was no significant difference of the personal influences between teens and college students $\left(\chi^{2}=\right.$ $7.570, p=0.056$ ). Overall $40.5 \%$ of total want to make their own decision for their jeans, and the remainder says friends(34.4\%), family(15.3\%), and celebrities(40.5\%). Of the teens, $38.5 \%$ and $42.4 \%$ of college students rely on personal preference as opposed to influence of others. They reported slightly different opinions about the influence of other people in that college students reported they were more susceptible to influence of friends and celebrities on apparel choices compared to high school students who reported family being a bigger influence(21.8\%) and celebrities being the least influence on teens' decision(5.1\%).

\subsection{Teens and College Students Decision Factors}

Table 5 shows the result of teens and college students' decision factors on purchasing denim jeans. According to the chi-square test at a $95 \%$ confidence level, there was no significant difference of decision factors between teens and college students $\left(\chi^{2}=3.673, p=\right.$ 0.299). Indifferently, the fit( $64 \%)$ was the most important factor for both groups in making decisions to select or reject purchasing denim jeans. Overall $69 \%$ of teens and $60 \%$ of college students expressed concern about fit. However, both groups were less concerned with the extrinsiccue of the brand when making a decision. This result indicates that intrinsic quality such as fit is important in making their decisions.

In addition, the most important decision factor for both groups, "fit" was further analyzed if fit problems were associated with their decisions for a pair of jeans. Table 6 shows the assessment result of various fit problems that are related to their decision factors. According to the chi-square test at a $95 \%$ confidence level, it was
Table 5. Teens and college students decision factors on purchasing denim jeans

\begin{tabular}{lcccccc}
\hline & \multicolumn{2}{c}{ Teen } & \multicolumn{2}{c}{ College } & \multicolumn{2}{c}{ Total } \\
\hline Decision Factors & $\mathrm{n}$ & $\%$ & $\mathrm{n}$ & $\%$ & $\mathrm{n}$ & $\%$ \\
\hline Cost & 14 & $18 \%$ & 24 & $28 \%$ & 38 & $23 \%$ \\
Brand & 7 & $9 \%$ & 9 & $11 \%$ & 16 & $10 \%$ \\
Color & 3 & $4 \%$ & 1 & $1 \%$ & 4 & $2 \%$ \\
Fit & 54 & $69 \%$ & 51 & $60 \%$ & 105 & $64 \%$ \\
\hline Total & 78 & $100 \%$ & 85 & $100 \%$ & 163 & $100 \%$ \\
\hline
\end{tabular}

Table 6. Teens and college students decision factor relating to fit problem

\begin{tabular}{|c|c|c|c|c|c|c|c|}
\hline \multirow[b]{2}{*}{ Fit Problems } & \multicolumn{2}{|c|}{ Teen } & \multicolumn{2}{|c|}{ College } & \multicolumn{2}{|c|}{ Total } & \multirow{2}{*}{$\gamma^{2}$} \\
\hline & $\mathrm{n}$ & $\%$ & $\mathrm{n}$ & $\%$ & $\mathrm{n}$ & $\%$ & \\
\hline Length & 33 & $42.3 \%$ & 58 & $68.2 \%$ & 91 & $55.8 \%$ & \\
\hline Waist & 14 & $17.9 \%$ & 13 & $15.3 \%$ & 27 & $16.6 \%$ & \\
\hline Hip & 4 & $5.1 \%$ & 5 & $5.9 \%$ & 9 & $5.5 \%$ & \\
\hline Thigh & 8 & $10.3 \%$ & 0 & $0.0 \%$ & 8 & $4.9 \%$ & \\
\hline Crotch & 1 & $1.3 \%$ & 2 & $2.4 \%$ & 3 & $1.8 \%$ & $23.662 *$ \\
\hline $\begin{array}{l}\text { The entire lower } \\
\text { body }\end{array}$ & 8 & $10.3 \%$ & 0 & $0.0 \%$ & 8 & $4.9 \%$ & \\
\hline No problem & 10 & $12.8 \%$ & 7 & $8.2 \%$ & 17 & $10.4 \%$ & \\
\hline Total & 78 & $100 \%$ & 85 & $100 \%$ & 163 & $100 \%$ & \\
\hline
\end{tabular}

found that teens and college students had significant differences of the fit problem areas $\left(\chi^{2}=23.622^{* *}, p<.05\right)$.

As shown in Table 6, teens expressed more fit problems around the waist $(17.9 \%)$ and thigh (10.3\%) compared to college students. Teens reported fit problems in the entire lower body(10.3\%) while college students reported none. Even though fit problems are commonly reported in all ages, teens become more frustrated at the failure of finding a right size for a pair of jeans. This result can be caused by the fact that apparel companies provide a certain style of jeans ignoring the existence of various body dimensions in the population.

\section{Conclusions and Suggestions}

In conclusion, the characteristics of current teens are very similar to college students. According to the previous study of teens shoppers(Palan \& Mallaieu, 2012), unlike adult shoppers, 59\% of teens primarily shop with friends. However, in this study we found that only $35 \%$ of teens and $34 \%$ of college students are influenced by their friends, while teens like college students desire to make their own decisions when they select and purchase denim jeans. Overall $40 \%$ of them want to make their own decision when purchasing their 
jeans. This indicates that teens and college students have similar characteristics of purchasing behavior. Teens, like college students, socialize and window shop with their friends, but are less likely to purchase. Both teens and college students do not rely on their peers to decide what they purchase. Celebrities are the least influential on purchasing decisions in both groups, which may be contradictory to most apparel company's celebrity marketing strategies.

Teens and college students prefer to purchase denim jeans from department stores, retail stores, and specialty stores in the mall. Malls have enticed teens into their social center and treated teens as independent and mature consumers to capitalize on their purchasing power(Kim \& Kim, 2005; Palan \& Mallalieu, 2012). Both groups browse on the internet and network through social media. However, in this study, neither group preferred to purchase denim jeans while shopping on the internet. This can be clarified with the characteristic of denim jeans that has to do with "a just right fit". Although high technology allows them to see virtual outfits and select options for a style, it is difficult to assess a just right fit without actually trying on jeans. Their preferred means of shopping for denim jeans is still by shopping in the mall where they can easily glance through and try outfits.

While teens and college students have shown the same preference of store type for a pair of jeans, teens and college students have different opinions about media influences. Overall, 50\% of teens cared less about media and celebrities. Teens liked to go out shopping for a pair of jeans while college students wanted to garner more ideas from fashion magazines and television. Even though some teens seek more information about styles of denim jeans from fashion magazines, they, like college students, were not influenced by television advertisements.

Teens and college students often use the Internet and social media for resources related to trends and fashion. However, neither the information provided through Internet nor social media impacted teens' or college students' decisions to select or reject buying apparel and current fashion. When we consider a current stream of social media and Internet usage for all age groups, this finding might be in opposition to the anticipation of increasing online sales in the apparel industry. However, it is necessary to understand the structure of denim jeans that requires a right "fit".

Teens, like colleges students, have focus on the same decision factors: fit $(63 \%), \operatorname{cost}(23 \%)$, brand(10\%) and color( $2 \%)$. Previous studies(Keller, 2001; Kim et al., 2009) emphasized brand as an important factor related to the strength of a consumer's ability to recognition of favorable attributes of the brand. However, we found that extrinsic cue of the brand was not a strong decision factor for the denim jeans. The most important factor in determining preference was "fit". While there were small variations in decision- making influence between teens and college-age participants, both groups identified "fit" as the most important factor when purchasing denim jeans.

Thus, denim manufacturers may benefit from focusing on quality of fit, social media influences and purchasing power of the population. In addition, it is inevitable for retailers and apparel manufacturers to develop marketing strategies that correspond with the influence of social media in shoppers of all ages. The development of an extrinsic brand should be integrated with the development of intrinsic quality and fit. This study is important to manufacturers and retailers as Generation $\mathrm{Y}$ ages into maturity and Generation $\mathrm{Z}$ become young adults. The size of both of these demographic groups will impact the retail market for the foreseeable future. For retailers and manufacturers to successfully meet their needs, they need to understand how they make decisions, the type of product they need specifically focused on fit, and the types of media that influence them.

This study was conducted in a region of the United States where denim jeans have always been important. From the denim first used by cowboys manufactured by Levi Strauss to Wranglers designed for cowboys, jeans have been an important part of a wardrobe for Texans. The sample in this study was limited to Generation Y and $Z$ female Texans.

This study repudiates many of the common beliefs about Generations $\mathrm{Y}$ and $\mathrm{Z}$. Although, they are both very social in both the real world and the Internet world of social media, they are still greatly influenced by their families and prefer to shop in a brick and mortar store. Because jeans are more than just a piece of clothing; but actually a statement of personality, fit is extremely important. No other garment has embodied the American psyche as denim jeans(Dorfman, 2013). As Generation Y matures as young professionals and Generation $\mathrm{Z}$ ages into teen-agers, a continuation of this study including the assessment of using avatars to assess fit when shopping online. Further, one of the interesting findings was these two generations are not influenced by celebrities. Another study which used another fashion product which does not have such an emotional connection to self would be interesting to test these findings. In addition, a nation-wide survey with a representative sample would increase the generalizability of this study.

\section{Acknowledgements}

This paper was supported by Wonkwang University in 2011.

\section{References}

Arthur, D., Sherman, C., Appel, D., \& Moore, L. (2006, Quarter 2). 
Why young consumers adopt interactive technologies. Young Consumers, 7(3), 33-38.

Berk, R. (2009). How do you leverage the latest technologies in your classroom. International Journal of Technology in Teaching and Learning, 6(1), 4.

Dorfman, M. (2013). Blue Jeans: An American phenomenon. Pop Goes the Culture. Retrieved October 27, 2013, from http:// cultureschlockonline.com/Articles/jeans.html

Engel, C. J., Bell, R. L., Meier, R. J., Martin, M. J., \& Rumpel, J. H. (2011). Young consumers in new marketing ecosystem: An analysis of their usage of interactive technologies. Academy of Marketing Studies Journal, 11(2), 23-44.

Grant, I. J., \& Stephen, G. R. (2005). Buying behavior of "tweenage" girls with key societal communicating factors influencing their purchasing of fashion clothing. Journal of Fashion Marketing and Management, 9(4), 450-467.

Herbst, F., \& Burger, C. (2002). Attributes used by young consumers when assessing a fashion product: A conjoint analysis approach. Journal of Family Ecology and Consumer Sciences, 30, 40-45.

Kang, S. (2006). Chasing generation Y. The Wall Street Journal. Retrieved September 15, 2013, from www.metroparkusa.com

Keller, K. L. (2001). Building customer-based brand equity. Marketing Management, 10(2), 4-19.

Kim, E. Y., \& Kim, Y. K. (2005). The effects of ethnicity and gender on teens' mall shopping motivations. Clothing and Textiles Research Journal, 23(2), 65-77.

Kim, E. Y., Knight, D. K., \& Pelton, L. E. (2009). Modeling brand equity of a U.S. apparel brand as perceived by generation $\mathrm{Y}$ consumers in the emerging Korean market. Clothing and Textiles Research Journal, 27 (4), 247-258.

Lee, Y. (August 20, 2013). 11 denim head to follow on Instagram. RAWRDENIM. Retrieved September 20, 2013, from http:// www.rawrdenim.com

Lindstrom, M. (2008). Buyology: Truth and Lies About Why We Buy. New York: Doubleday.

Noble, S. M., Haytko, D. L., \& Phillips, J. (2009). What drives college-age Generation Y consumers? Journal of Business
Research, 62(6), 6117-6128.

O'Keeffe, G. S., Clarke-Pearson, K., and Council on Communications and Media. (2011). The Impact of Social Media on Children, Adolescent, and Families. Pediatrics, 127, 800-805.

Palan, K., \& Mallalieu, L. (2012). A troubled relationship: an exploration of mall retailers and teen shoppers' thoughts, behaviors, and coping strategies as they interact with each other. Young Consumers: Insight and Ideas for Responsible Markets, 13(3), 242-254.

Rahman, O. (2011). Understanding consumers' perceptions and buying behaviors: Implications for denim jeans design. Journal of Textile and Apparel, Technology and Management, 7(1). Retrieved October 24, 2013, from http://ojs.cnr.ncsu.edu/

Ramos, J. (2013). Students stuck in social media bubbles limiting awareness. The Corsair, 106(8). Retrieved October 25, 2013, from http://www.thecorsaironline.com

Roche, T., \& Williams, S. (2006). The fast and fascinating rise of generation Y. American Banker 171(63), 2.

Royer, L., Jordan, J., \& Harrison, M. (2005). How financially literate are today's youth? Their current practices and what we need to know as educators. The Forum for Family and Consumer Issues, 10(1), Retrieved October 24, 2013, from http://ncsu.edu/ffci

Schroer, W. (2012). Generation X, Y, Z and others. The Social Librarian. Retrieved September 15, 2013, from http://www.socialmarketing.org

Shankar, V., Venkates, A., Hofacker, C., \& Naik, P. (2010). Mobile marketing in the retailing environment: Current insights and future research avenues. Journal of Interactive Marketing, 24(2), 111120.

Wang, L. (May 2, 2013). Premium denim's tentative comeback. The Business of Fashion. Retrieved September 20, 2013, from http:// www.businessoffashion.com

Williams, K. C., \& Page, R. A. (2011). Marketing to the generations. Journal of Behavioral Studies in Business, 5(1), 1-17.

(Received 25 September 2013; 1st Revised 14 October 2013; 2nd Revised 11 November 2013; 3rd Revised 13 November 2013;

Accepted 1 November 2013)

Copyright (C) The Society of Fashion and Textile Industry. 2013. This is an open access article distributed under the terms and conditions of the Creative Commons Attribution Non-Commercial license (http://creativecommons.org/licenses/by-nc/3.0/), which permits unrestricted non-commercial use, distribution, and reprodction in any medium, provided the original work is properly cited. 